\title{
A COMBINED OPEN AND PERCUTANEOUS TECHNIQUE FOR REPAIR OF TENDO ACHILLIS
}

\author{
COMPARISON WITH OPEN REPAIR
}

MASAAKI KAKIUCHI

From Osaka Police Hospital, Osaka, Japan

A combined open and percutaneous operative technique has been devised for repair of tendo Achillis. This minimises postoperative scarring. We compared the long-term results of 12 patients treated by this method with the results of 10 who had undergone an open repair.

The combined open and percutaneous repair gave significantly better relief of symptoms during everyday activities $(\mathrm{p}<0.05)$, better single-limb hopping $(p<0.02)$ and a greater chance of returning to sport $(p<0.01)$. There were no significant differences between the two treatments as regards the active range of ankle motion, calf circumference or the ability to stand on tiptoe. The new technique gave better cosmetic results.

J Bone Joint Surg [Br] 1995:77-B:60-3.

Received I3 January 1994: Accepted 9 June 1994

The treatment of a closed rupture of tendo Achillis should restore the original length of the tendon, minimise adhesions between it and the surrounding tissues, and give a good cosmetic result. Conservative treatments such as cast immobilisation or percutaneous repair (Ma and Griffith 1977) minimise tendon adhesions and wound scarring, but may not achieve satisfactory contact of the tendon stumps. Because of this, healing may be delayed and the original length of the tendon may not be accurately restored. Rerupture or tendon lengthening will impair the function of the triceps surae.

We therefore devised a combined open and percutaneous technique and now describe the details and long-term results.

\section{PATIENTS AND METHODS}

From January 1985 to December 1988 at Osaka Police Hospital combined open and percutaneous repair was performed on 20 patients and open repair on 14. The first six patients had the new technique, and in the other 28 the new

M. Kakiuchi, MD, Head of the Department of Orthopaedic Surgery Osaka Police Hospital. 10-31 Kitayama-cho, Tennoji-ku, Osaka 543, Japan.

(1)1995 British Editorial Society of Bone and Joint Surgery

$0301-620 X / 95 / 1907 \$ 2.00$

and the standard open repairs were alternated. All 34 patients had fresh closed ruptures of tendo Achillis with a palpable gap, and no history of injury on the contralateral side.

Seven patients (five combined open and percutaneous repairs and two open repairs) were lost to follow-up. Between July 1992 and June 1993 we examined 12 of the 15 remaining patients $(80 \%)$ who had had combined open and percutaneous repairs, and 10 of the remaining $12(83 \%)$ who had had open repairs.

Technique of combined open and percutaneous repair. The patient is placed in a prone position after induction of lumbar spinal anaesthesia. No tourniquet is used. A $2 \mathrm{~cm}$ longitudinal paramedian incision is made just above the palpable tendon gap to provide a direct view of the rupture. The fascia and paratenon are incised longitudinally to expose the stumps of the tendon. The incision may require extension proximally or distally in some cases.

Two suture guides made of $2 \mathrm{~mm}$ Kirschner wire to provide stiffness (Fig. 1) are then inserted, one medially and the other laterally, between the tendon and the paratenon proximal to the rupture site (Fig. 2a). A long straight needle threaded with a non-absorbable suture (Tefdesser II, USP 1; Kono Seisakusho Co Ltd. Chiba. Japan) is passed transversely through the skin. the intact tendon, and the holes in the suture guides (Fig. 2b). This blind part of the
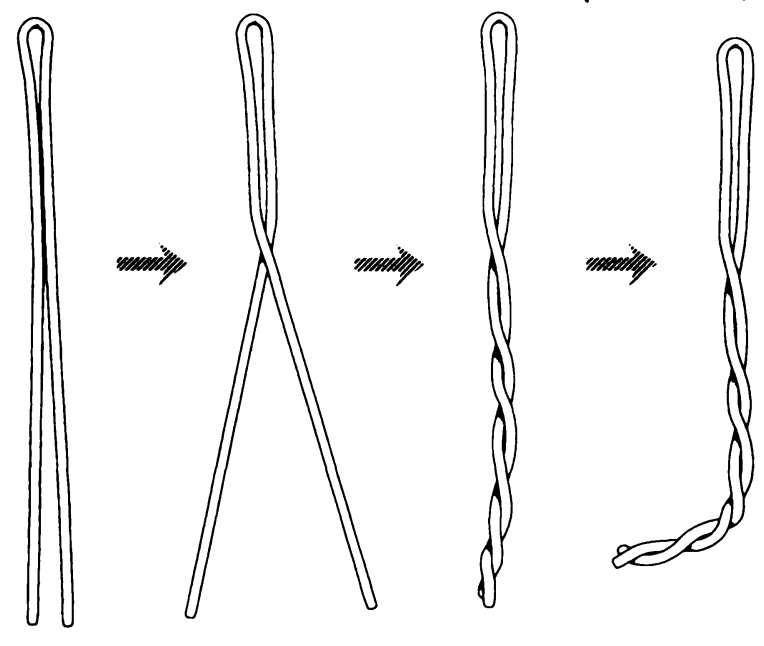

Fig. 1

The suture guide is made by bending a $2 \mathrm{~mm}$ Kirschner wire and twisting its ends together. 
A COMBINED OPEN AND PERCUTANEOUS TECHNIQUE FOR REPAIR OF TENDO ACHILLIS

61

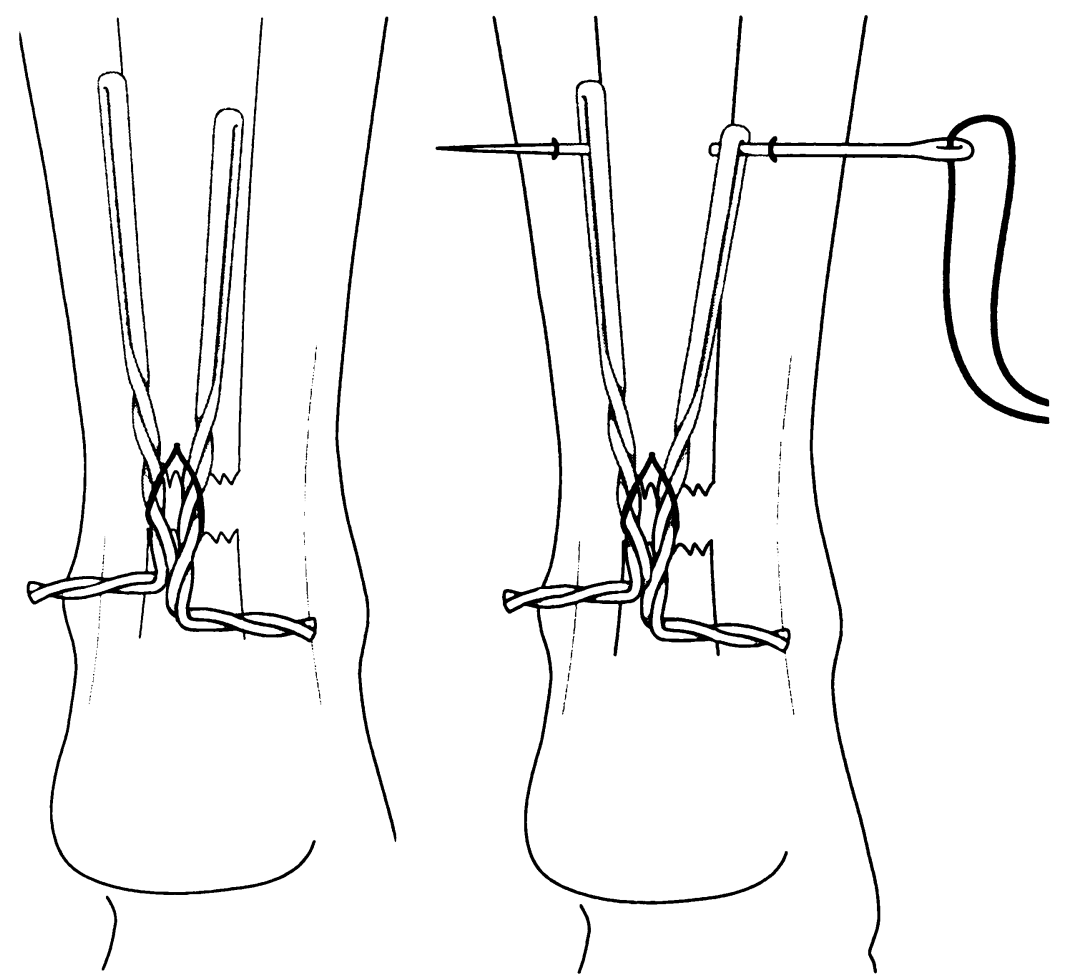

Fig. Ia

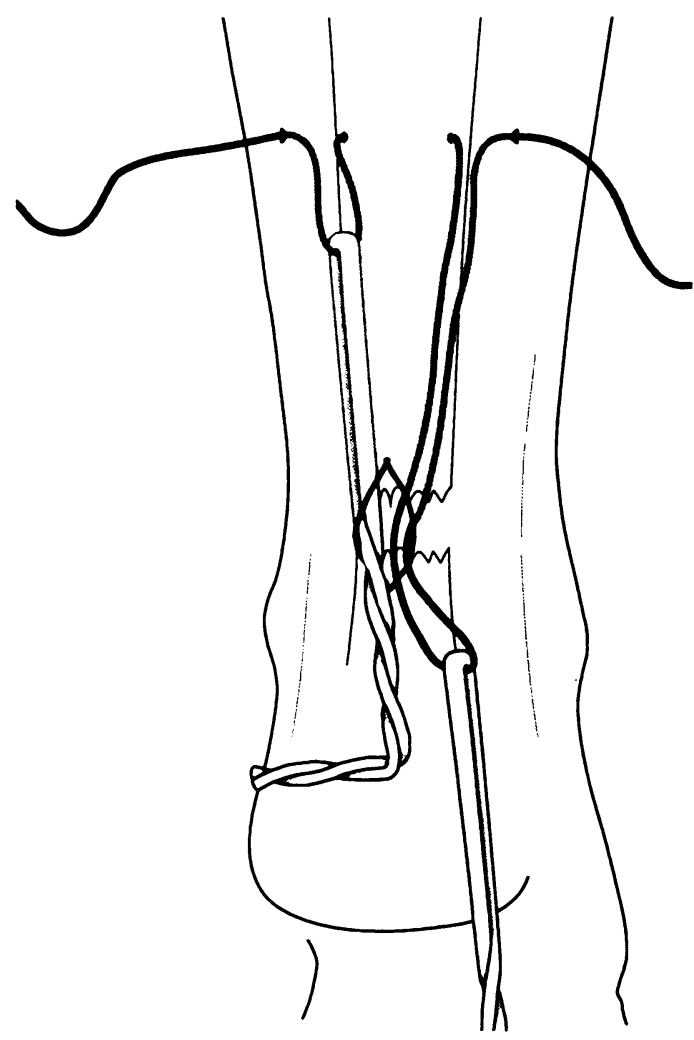

Fig. 2d

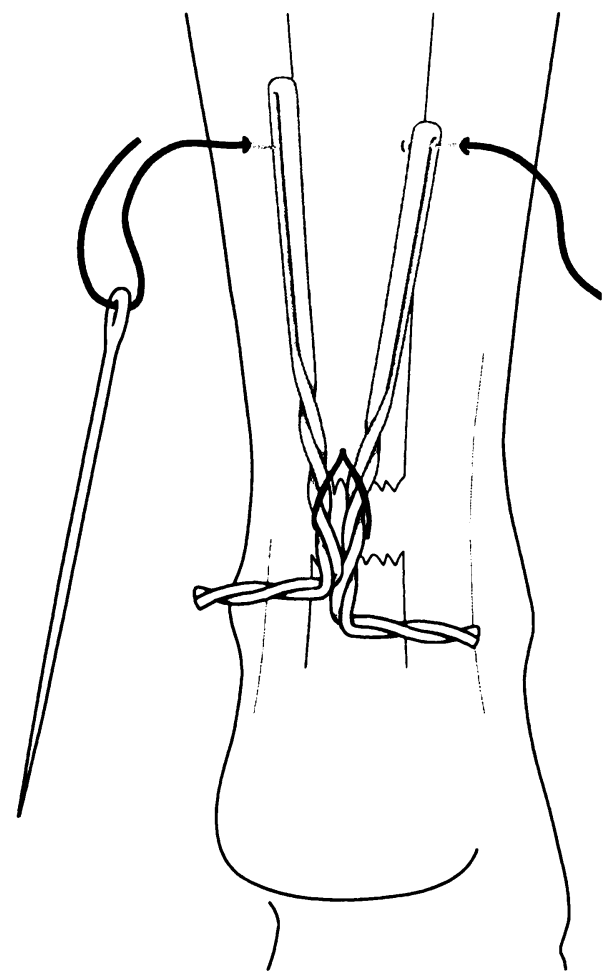

Fig. 2c

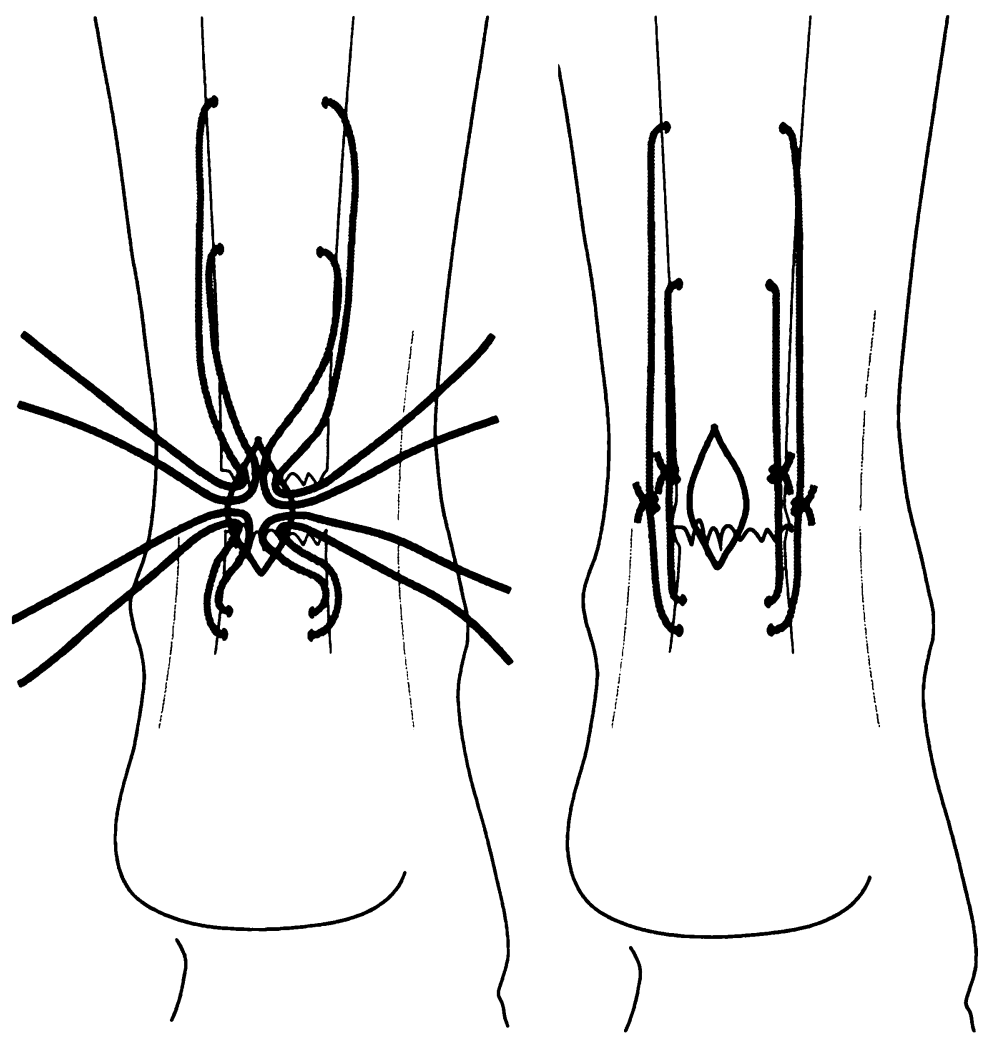

Fig. $2 f$

Diagrams of the stages of combined open and percutaneous repair of ruptured tends Achilles (see text).

VOL. 77-B. N(). I. JANUARY 1995 
procedure requires the surgeon to direct the needle repeatedly against the suture guide, holding one in each hand. When the needle tip slips into the guide hole this can easily be detected. When the suture is in place (Fig. 2c), both ends are drawn down into the wound by pulling on the guide wires (Fig. 2d). This procedure is repeated at two different levels on both the proximal and distal stumps of the tendon (Fig. 2e). The ankle is then held at $20^{\circ}$ to $30^{\circ}$ plantar flexion and the knee flexed to $90^{\circ}$ while the sutures are tied. Direct observation confirms that the space between the two stumps has been eliminated (Fig. 2f).

The knots in the sutures are covered with paratenon to prevent contact with the fascia or subcutaneous tissues and the cut ends of the paratenon and fascia are sutured in separate layers with absorbable sutures (Dexon Plus, USP 3-0, Davis and Geck, American Cyanamid Company, Wayne, New Jersey). No drain is used, the skin is sutured and dressed and a well-padded above-knee cast is applied with the foot in about $30^{\circ}$ of equinus and the knee flexed to about $45^{\circ}$.

Technique of open repair. Standard open repair is performed with a longitudinal paramedian incision through the skin, fascia and paratenon to expose the rupture and tendon stumps through which sutures are to be placed. The tendon repair is by Bunnell-type non-absorbable sutures (Tefdesser II, USP 1). The paratenon and fascia are sutured independently using absorbable material (Dexon Plus, USP 3-0).
After wound closure, a well-padded above-knee cast is applied as for the other type of repair.

Postoperative management. The above-knee part of the cast was trimmed posteriorly on the day of the operation, to allow full knee flexion but still limit extension to less than $45^{\circ}$. After about one week it was replaced by a below-knee cast for another three weeks. Full weight-bearing was allowed after six weeks. Table I shows the means and ranges for these periods and also the timing of return to sport.

At follow-up we recorded subjective symptoms and return to sport and measured the circumference of both calves and the active range of ankle motion with the knee fully extended. The ability to stand on tiptoe was assessed, as was single-limb hopping with the knee slightly flexed.

\section{RESULTS}

Early complications. Of the 20 patients who had the new technique, one had mild transient numbness on the lateral aspect of the foot. These symptoms did not affect his everyday activities and they had settled by the third month after surgery. There were no other early complications.

Long-term results. These are shown in Table II. There had been no reruptures in either group. The combined open and percutaneous repair was superior to open repair with statistically significant differences in the incidence of symptoms

Table I. Details of the patients reviewed for the long-term study

\begin{tabular}{|c|c|c|}
\hline & $\begin{array}{l}\text { Combined open and } \\
\text { percutaneous repair }\end{array}$ & Open repair \\
\hline Number of patients & 12 & 10 \\
\hline Male:female & $10: 2$ & $9: 1$ \\
\hline $\begin{array}{l}\text { Age at operation in years } \\
\text { (mean: range) }\end{array}$ & 35.0 (19 to 49$)$ & $35.4(23$ to 55$)$ \\
\hline $\begin{array}{l}\text { Timing of repair after injury } \\
\text { in days (mean; range) }\end{array}$ & 5.1 (1 to 9$)$ & 4.5 (3 to 7$)$ \\
\hline $\begin{array}{l}\text { Follow-up period in years } \\
\text { and months (mean; range) }\end{array}$ & $5 \mathrm{yr} 1 \mathrm{mth}(4 \mathrm{yr} 1 \mathrm{mth}$ to $7 \mathrm{yr} 5 \mathrm{mth})$ & $5 \mathrm{yr} 6 \mathrm{mth}$ ( 3 yr $9 \mathrm{mth}$ to $7 \mathrm{yr} 5 \mathrm{mth}$ ) \\
\hline \multicolumn{3}{|l|}{ Activity which caused the injury } \\
\hline Kendo (Japanese fencing) & 7 & 4 \\
\hline Judo & - & 1 \\
\hline Karate & - & 1 \\
\hline Tennis & 1 & 1 \\
\hline Badminton & 1 & - \\
\hline Running & 1 & 1 \\
\hline Lifting heavy object & 1 & - \\
\hline Others & 1 & 2 \\
\hline $\begin{array}{l}\text { Period of cast immobilisation after } \\
\text { operation in days (mean; range) }\end{array}$ & 25.3 (22 to 26$)$ & 28.4 ( 25 to 39$)$ \\
\hline $\begin{array}{l}\text { Timing of full weight-bearing after } \\
\text { operation in days (mean; range) }\end{array}$ & $51.6(45$ to 57$)$ & $54.8(49$ to 62$)$ \\
\hline $\begin{array}{l}\text { Timing of returning to preinjury sport } \\
\text { after operation in weeks (mean; range)* }\end{array}$ & $21.6(16$ to 29$)$ & $25.2(22$ to 27$)$ \\
\hline
\end{tabular}

* some patients did not participate in sport (Table II) 
Table II. Long-term results in 22 patients

\begin{tabular}{|c|c|c|c|}
\hline & $\begin{array}{l}\text { Combined open and } \\
\text { percutaneous repair }\end{array}$ & Open repair & $p$ value of difference* \\
\hline \multicolumn{4}{|l|}{ Symptoms } \\
\hline None & 10 & 4 & $\mathrm{p}<0.05$ \\
\hline Stiffness & 2 & 3 & \\
\hline Discomfort & - & 1 & \\
\hline Pain & - & 2 & \\
\hline \multicolumn{4}{|l|}{ Calf circumference $\dagger$} \\
\hline Reduced by less than $10 \mathrm{~mm}$ & 10 & 7 & NS \\
\hline Reduced from 10 to $20 \mathrm{~mm}$ & 2 & 3 & \\
\hline \multicolumn{4}{|l|}{ Active range of ankle motion $\dagger$} \\
\hline Normal & 10 & 7 & NS \\
\hline Altered & 2 & 3 & \\
\hline \multicolumn{4}{|l|}{ Standing on tiptoe $\dagger$} \\
\hline Normal & 12 & 9 & NS \\
\hline Impaired & - & 1 & \\
\hline \multicolumn{4}{|l|}{ Hopping with the knee slightly flexed $\dagger$} \\
\hline Same as normal limb & 10 & 3 & $<0.02$ \\
\hline Less than normal limb & 2 & 7 & \\
\hline \multicolumn{4}{|l|}{ Change in sport activities } \\
\hline Same or increased & 9 & 1 & $<0.01$ \\
\hline Decreased & 1 & 4 & \\
\hline No participation for other reasons & 2 & 5 & \\
\hline
\end{tabular}

during everyday activities, single-limb hopping and returning to sport. Differences were not statistically significant for active range of ankle motion, ability to stand on tiptoe, or maximum calf circumference.

The ability to hop on the injured leg with the knee slightly flexed was mildly impaired in two patients after combined open and percutaneous repair and in seven after open repair, and appeared to correlate with an impaired range of motion of the ankle. After the new technique, one patient had typical tendon lengthening with increased dorsiflexion and reduced plantar flexion. After open repair, two patients had decrease in both dorsiflexion and plantar flexion, and one had decreased dorsiflexion only. In the 13 patients with no impairment (ten new repairs and three standard repairs) 12 had the same range of motion as on the uninjured side; one showed a decrease in range of dorsiflexion of the ankle.

\section{DISCUSSION}

The aim of treatment is the recovery of full normal function of the triceps surae. Postoperative reduction in muscle power may be due to disuse muscle atrophy or to failure to restore the original tendon length. Power may be improved by physical exercise, but lengthening has an unfavourable prognosis, since it prevents the triceps surae from working effectively. One sign of this is increased dorsiflexion of the ankle, and this tends to occur after conservative treatment in plaster or closed percutaneous repair, because the ruptured ends of the tendon cannot be seen to be in satisfactory contact. Lengthening is probable, and consequent delay in healing may lead to an increased risk of rerupture.

A standard open repair gives good exposure and can usually restore the original tendon length. The extensive exposure, however, causes considerable scarring which may impair tendon motion and therefore interfere with the range of ankle movements and the transmission of power to the calcaneus.

The one case of lengthening of the tendon after the new technique occurred despite the absence of space between the two stumps at operation, and the probable reason was that the sutures were passed through injured parts of the tendon. Where tendon injury is extensive, with a brush-like appearance of the proximal stump, care must be taken to pass the sutures through a more proximal, intact part of the tendon.

Transient impairment of sural nerve function occurred in only one instance and may have been due to repeated piercing of the skin by the needle in a search for the suture guide. The guide itself is placed deep to the paratenon, and there is therefore no risk of trapping a subcutaneous nerve in the suture itself. The author is now developing a guide, made by drilling a hole near the tip of a flat nerve dissector which may prove easier to use than the Kirschner wire.

No benefits in any form have been received or will be received from a commercial party related directly or indirectly to the subject of this article.

\section{REFERENCE}

Ma GWC, Griffith TG. Percutaneous repair of acute closed ruptured Achilles tendon: a new technique. Clin Orthop 1977:128:247-55. 